\title{
Ultrastructure Study on the Effect of Alternating Magnetic Field on Mice Liver
}

\author{
Neveen Hussein Mahmoud \\ Department of Zoology-Faculty of Science, Alazhar University
}

\begin{abstract}
Recently, it is recorded that electromagnetic field (E.M.F) is considered dramatically as one of the most dangerous environmental pollutant especially among the developing industrialization societies. The present study aimed to investigate the effect of continuous daily exposure to alternating magnetic field (AC/E.M.F). Adult male mice were classified into three groups. The first group was kept as control. The second group received (50 HZ/AC of 2mT) daily for 20 days. The third group received the same dose and kept for another one month (post treatment) without exposure. Histological and Ultrastuctural studies were carried out on liver tissue using light and electron microscopes.

The microscopic examination of the liver specimen of the second group revealed degenerated liver tissue when compared to control group, shrinking rough endoplasmic reticulum, swollen degenerated mitochondria and pyknotic nuclei. Examination of the liver specimens of the third group showed more severe degeneration in comparison with the second group and no sign of recovery was observed.
\end{abstract}

\section{Introduction}

Advances in medical instrumentation and concerns about exposure to E.M.F have stimulated research on its effect on organisms and biological materials (Tenforde,1979; Maret, 1986; and Simon, 1992.)

Many organisms are also known to posses inclusions of magnetic material, (Frankel,1991). Alternating magnetic field is produced by alternating currents (AC) having a frequency range from zero to 300 hertz (HZ). The fundamental quantities describing a magnetic field are the field strength (ampere/meter, $\mathrm{A} / \mathrm{m}$ ) and the magnetic flux density Tesla, $\mathrm{T} \quad \mathrm{A} / \mathrm{m}=1.26$ $\mu \mathrm{T}$ (Anderson and kaune, 1988.)

Experimental studies on animals are important with reservations as to the conclusions that might be drawn with respect to possible effect of E.M.F. on human health. Histological studies can provide an understanding of possible mechanisms of biological interaction (ICNIRR,2004). Documents of NRPB, 2004 reported slight changes in spermatogenesis and embryogenesis in mice exposed to $1.5 \mathrm{~T}$ for $30 \mathrm{~min}$.

A recent study in Canada (Rivard and Deadman,2003) reported a relative risk of childhood leukaemia following maternal occupational exposure during pregnancy to (E.M.F.)

Mikaelian et al (1989), Gorczynska and Wegrzynowicz,(1991) and Radi et al., (1999) found that the exposure of male mice to AC/EMF of $10 \mathrm{mT}$ revealed focal areas of degenerated hepatocytes with vacuolated cytoplasm and various changes in the cyto-plasmic organelles. Nuclei showed irregular outlines, clumping and condensation of heterochromatin as well as shrinkage and pyknosis.

Mitochondria appeared swollen with disrupted membranes.

Mohamed et al.,(2001) investigated the effect of longterm exposure to low frequency (E.M.F.) on mice brain (50 HZ ) for 50 days. They found that the ultrastucture examination of the cerebral cortical layers showed wider spaces 
between the folia of the molecular layer and the Purkinje cells displayed variable degrees of cell loss.

\section{Materials and Methods}

The present study was carried out on thirty (30) healthy male mice, divided into three groups :

Group (1) : 10 normal control mice sham exposed to magnetic field

Group (2) : 10 mice were exposed to alternating current (AC) electromagnetic field (50 HZ/AC) with flux density $2 \mathrm{mT}$, 8 hours daily, for 20 days, then sacrificed immediately after the end of exposure

Group (3) : 10 mice were exposed to alternating current (AC) electromagnetic field $(50 \mathrm{HZ} / \mathrm{AC} / 8$ hours $)$ with flux density $2 \mathrm{mT}$ daily for 20 days and kept for another month without exposure.

For alternating magnetic fields induction, exposure chamber was designed to obtain homogenous alternating current magnetic fields $50 \mathrm{~Hz}$ frequency within it where the mice were placed in a well ventilated glass container.

Fresh liver specimens were removed from all studied mice, cut into small pieces $(0.5-1 \mathrm{~mm})$ and immediately fixed in cold $5 \%$ glutraldhyde in $0.1 \mathrm{ml}$ sodium cacodylate buffer, and kept over night at 4 ${ }^{\circ} \mathrm{c}$. After washing in the same buffer specimens were post-fixed in $1 \%$ osmium tetra-oxide then embedded in plastic resin. Semithin sections ( $1 \mu$ in thickness) were cut using ultramicrotome, mounted on glass slide and stained with toluidine blue for light microscope examination.

Ultra-thin sections were also cut, mounted on coated copper grids, stained with uranyl acetate and lead citrate for transmission electron microscope examination.

\section{Results}

\section{Light microscopy:}

Studies of semithin sections of group(2) mouse liver following E.M.F. exposure for 20 days revealed affected liver tissue with degenerated, necrotic focal areas, pyknotic nuclei and degenerated congested blood sinusoid (fig.2)

Semithin sections of mouse liver which was exposed to E.M.F. for 20 days and kept for another month without exposure group(3) appeared severely affected. Hepatocytes lost their normal architecture with vacuolated cytoplasm and darkly stained nuclei (fig.3).

\section{Electron microscopy:}

Ultrathin sections of normal mouse liver group(1) control showed normal hepatocytes and normal nucleus separated by sinusoid lining cells with the space of disse between the hepatocyte surface and the lining cells (fig.4). The cytoplasm contained large number of free ribosomes, scattered mitochondria and well developed rough endoplasmic reticulum (rER) extending throughout the cytoplasm surrounding the nucleus. Dense glycogen granules were spread out in the cytoplasm and also few lysosomes were noticed. A prominent nucleus was observed with prominent nucleoli and a distinct nuclear membrane (fig. $5 \& 6$ )

Group(2) showed marked reduction in cytoplasmic organelles, reminent of fragmented rough endoplasmic reticulum and mitochondria with disruptive cristae. The nuclear membrane was irregular with few dense heterochromatin surrounding a nucleoli (fig.7\&8). Severe reduction in (rER), pyknotic nuclei and few secretory granules were observed (fig.9).

Group(3) which was kept for another month without exposure, the ultrathin sections of mouse liver showed highly affected hepatocytes. An opaque cytoplasmic matrix, severe reduction in cytoplasmic organelles, depletion of glycogen, few mitochondria and large electrotranslucent spaces were observed. Signs of nuclear pyknosis and absence of cell membrane were clearly seen (fig.10\&11). Group(3) also showed swollen mitochondria with disrupted cristae, few cisternae of (rER), degenerated shrinked nucleus with dense heterochromatin, (fig.12) and disrupted nuclear membrane (fig.13). the previous treatment also showed accumulation of dense chromatin at the periphery of the 


\section{Neveen Hussein Mahmoud}

nuclear membrane (fig.14) and depletion of chromatin material in the cytoplasm with increasing of electrotranslucent cytoplasmic vacuoles (fig.15).

\section{List of illustration}

(fig.1) a light micrograph of a semithin section of control mouse liver group(1) showing normal histological and cytological features. The strands of hepatocytes are separated by blood sinusoids. Note the normal appearance of hepatocytes which contain vesicular cytoplasm and round nuclei. (toluidine blue $\times 1000$ ).

(fig.2) a light micrograph of a semithin section of treated mouse liver group(2) showing the degenerated and necrotic focal areas, pyknotic nuclei $(\mathrm{P})$ and degenerated congested blood sinusoids(B.S) (toluidine blue $\times 1000$ ).

(fig.3) a light micrograph of a semithin section of treated mouse liver group(3) showing severely affected hepatocytes that lost their normal architecture. Vacuolated cytoplasm (V) and nuclei are darkly stained. (toluidine blue $\times 1000$ ).

(fig.4). An electron micrograph of ultrathin section of normal mouse liver group(1)showing two adjacent hepatocytes with normal nucleus (N) separated by sinusoid lining cells (S) with the space of disse (D) between the hepatocyte surface and the lining cells. $(\times 8000)$.

(fig.5,6). Electron micrographs of ultrathin section of control mouse liver group (1) showing normal hepatocytes. The cytoplasm contains large number of free ribosomes and scattered mitochondria (M). Well developed rough endoplasmic reticulum (rER). Dense glycogen granules $(G)$ and few lysosomes (L). A prominent nucleus (N) which contains prominent nucleoli and a distinct nuclear membrane $(\times 4000 \& \times 8000)$.

(fig.7,8).An electron micrographs of ultrathin section of treated liver group(2) showing remanent of fragmented rough endoplasmic reticulum (rER) and mitochondria with disruptive cristae. Irregular nuclear membrane with few dense heterochromatin surrounding a nucleoli. $(\mathrm{H})(\times 12000 \& \times 20000)$

(fig.9). An electron micrograph of ultrathin section of treated mouse liver group(2) showing severe affected hepatocytes, severe reduction in (rER), pyknotic nuclei (P) and few secretory granules $(\mathrm{F}) .(\times 20000)$

(fig.10,11). An electron micrographs of ultrathin section of treated mouse liver group(3) showing an opaque cytoplasmic matrix, severely reduced cytoplasmic organelles, depletion of glycogen, large electrotranslucent spaces, few mitochondria, signs of nuclear pyknosis and absence of cell membrane boundaries. $(\times 6000 \& \times$ 5000)

(fig.12). Electron micrograph similar to the previous treatment, showing degenerated shrinked nucleus with dense heterochromatin, swollen mitochondria with disrupted cristae and few cisternae of $(\mathrm{rER})(\times 12000)$

(fig.13) Electron micrograph similar to the previous treatment, showing remaining of fragmented (rER) and irregular disrupted nuclear membrane

(fig.14). The same previous treatment showing irregular disrupted nuclear membrane and accumulation of dense chromatin at the periphery of the nuclear membrane. $\quad(\times 20000)$

(fig.15). The same previous treatment showing disruption of nuclear membrane and depletion of chromatin material in the cytoplasm. Notice the increasing of electrotranslucent cytoplasmic vacuoles(V). (× 20000) 
Ultrastructure Study on the Effect of..........
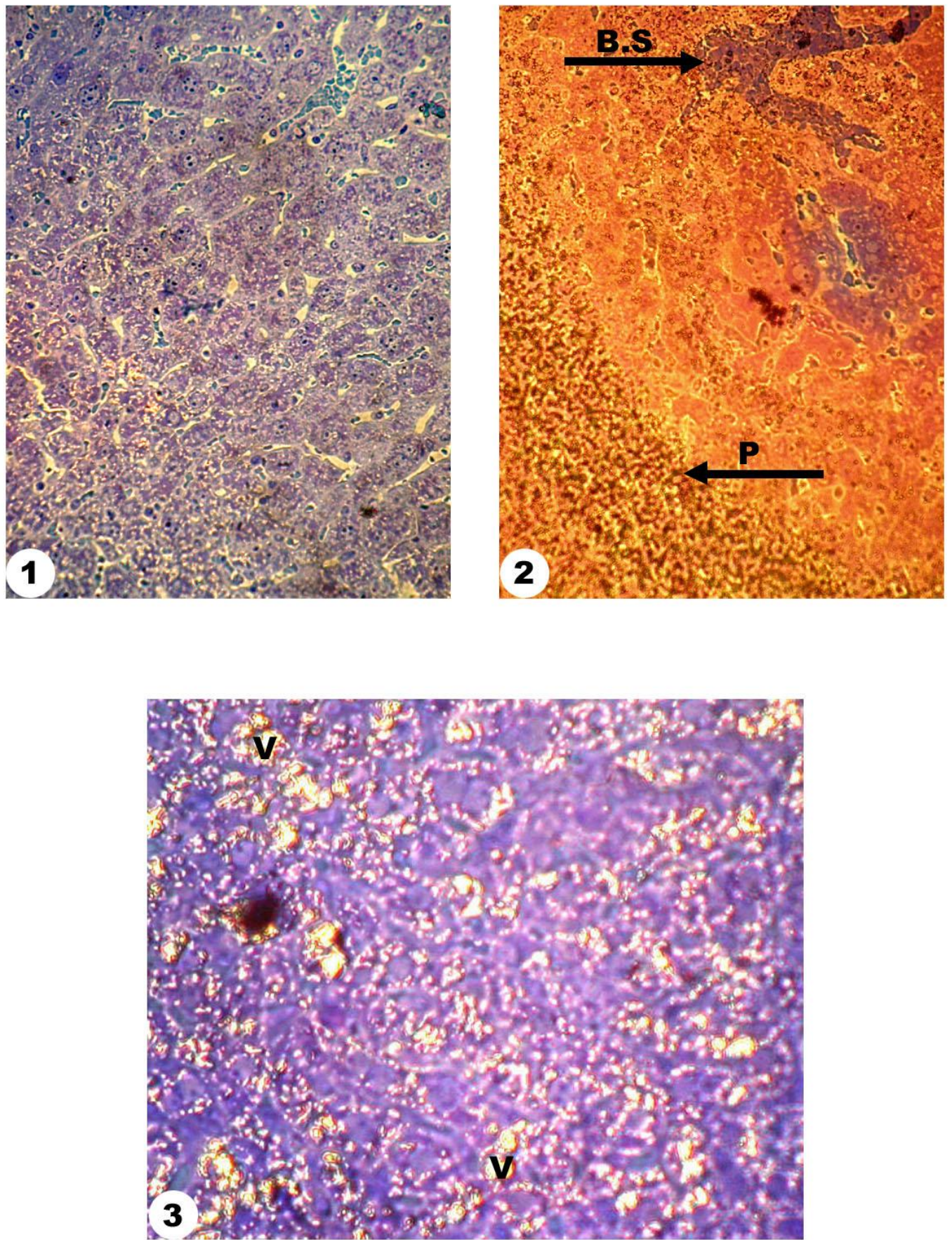

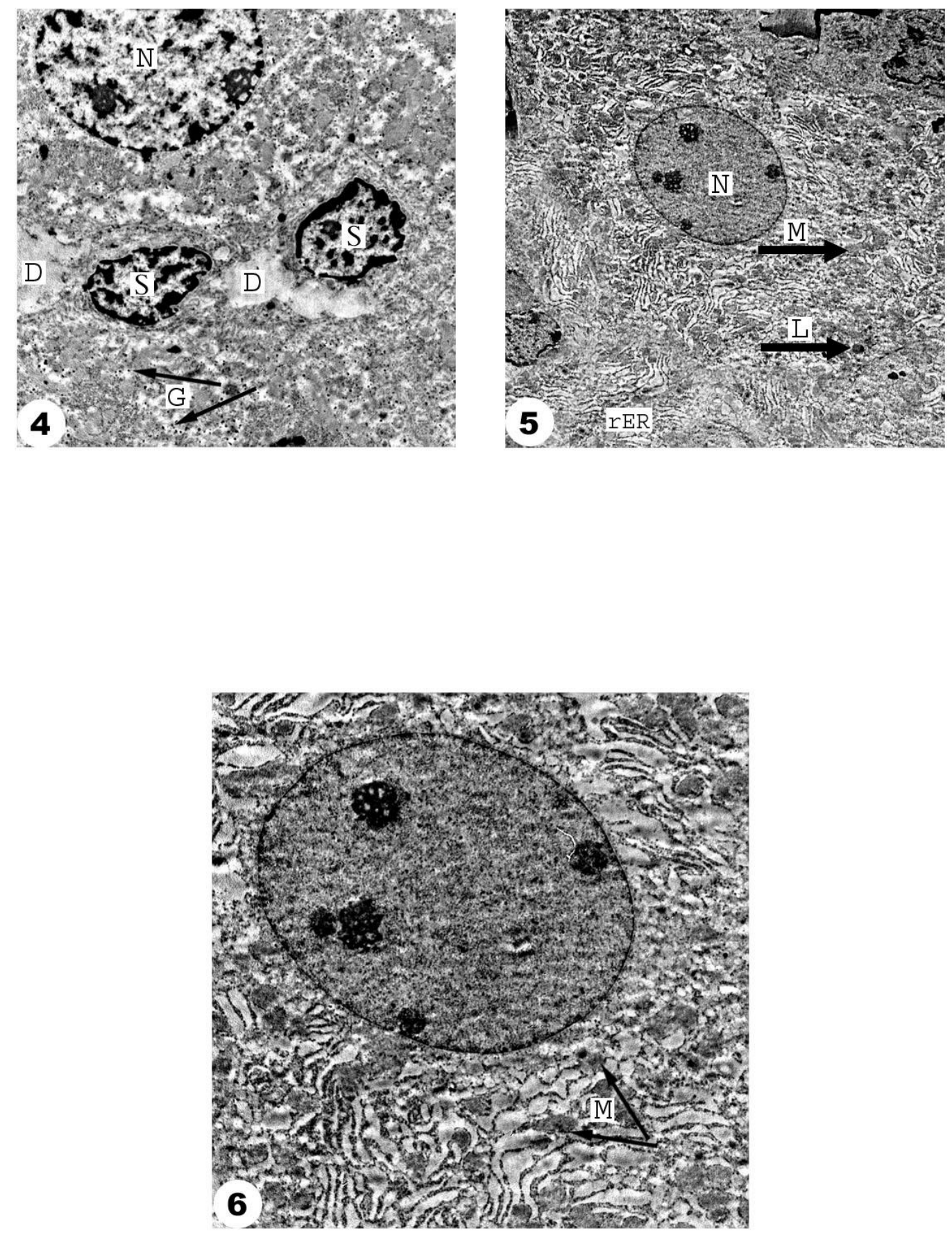
Ultrastructure Study on the Effect of..........
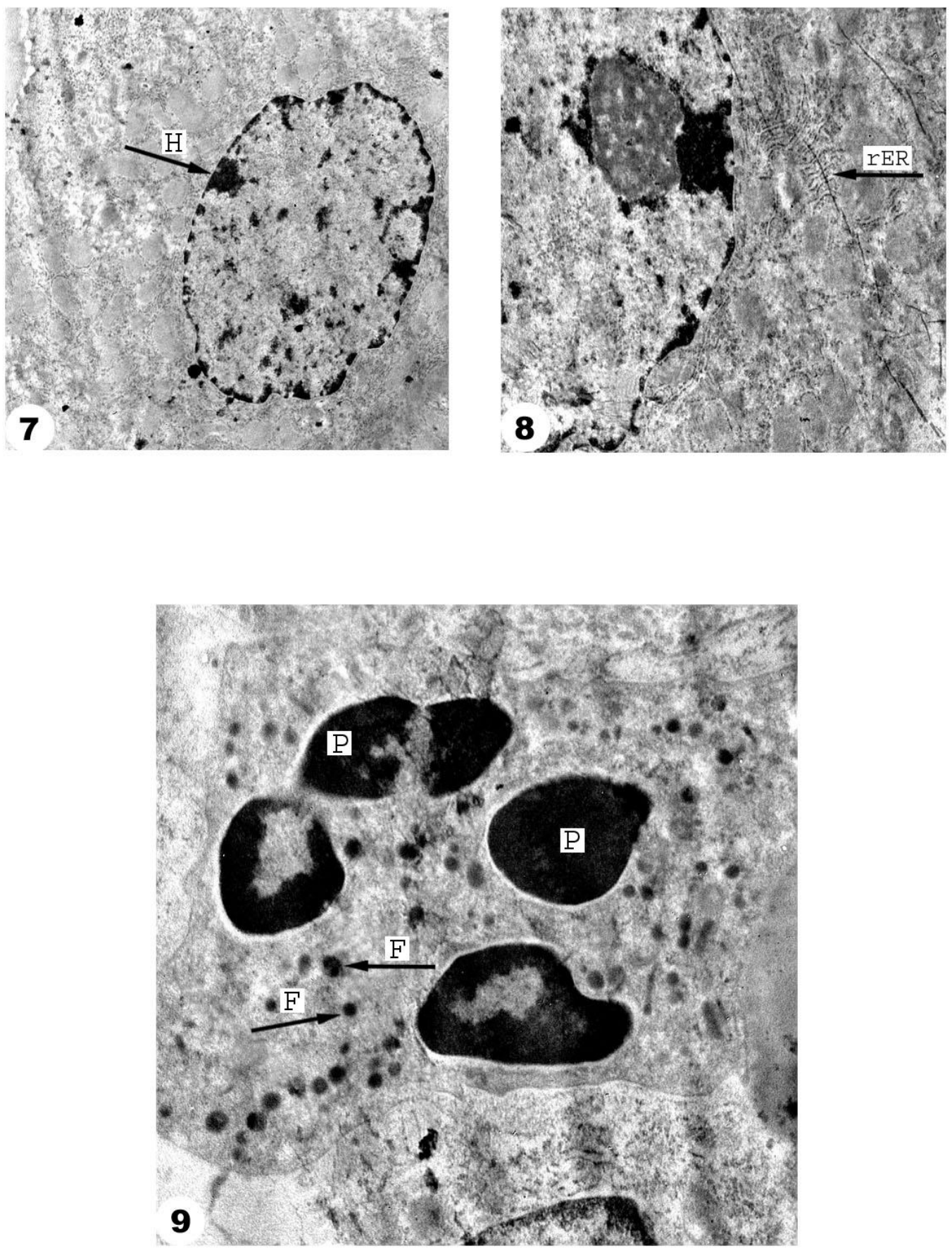

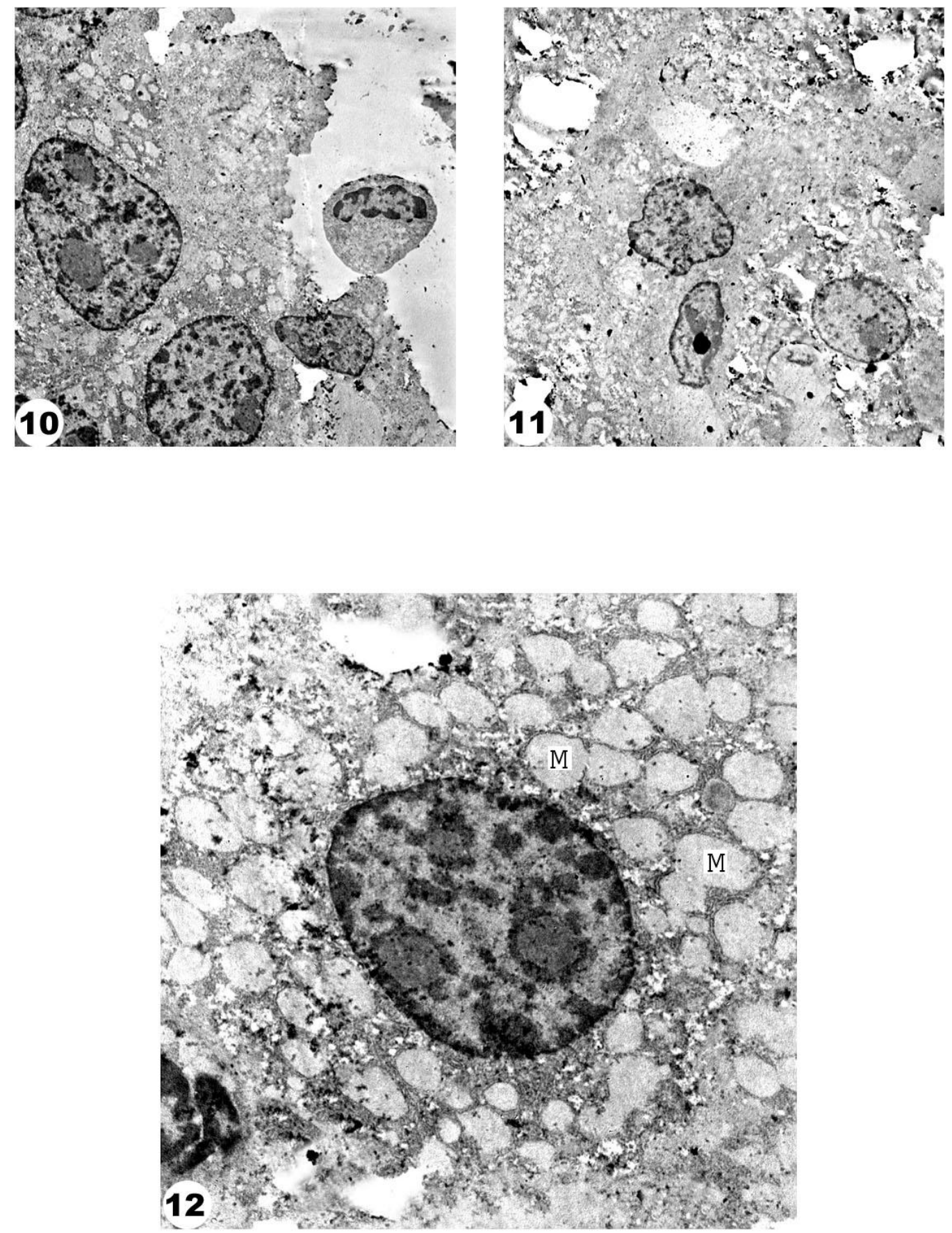
Ultrastructure Study on the Effect of.........
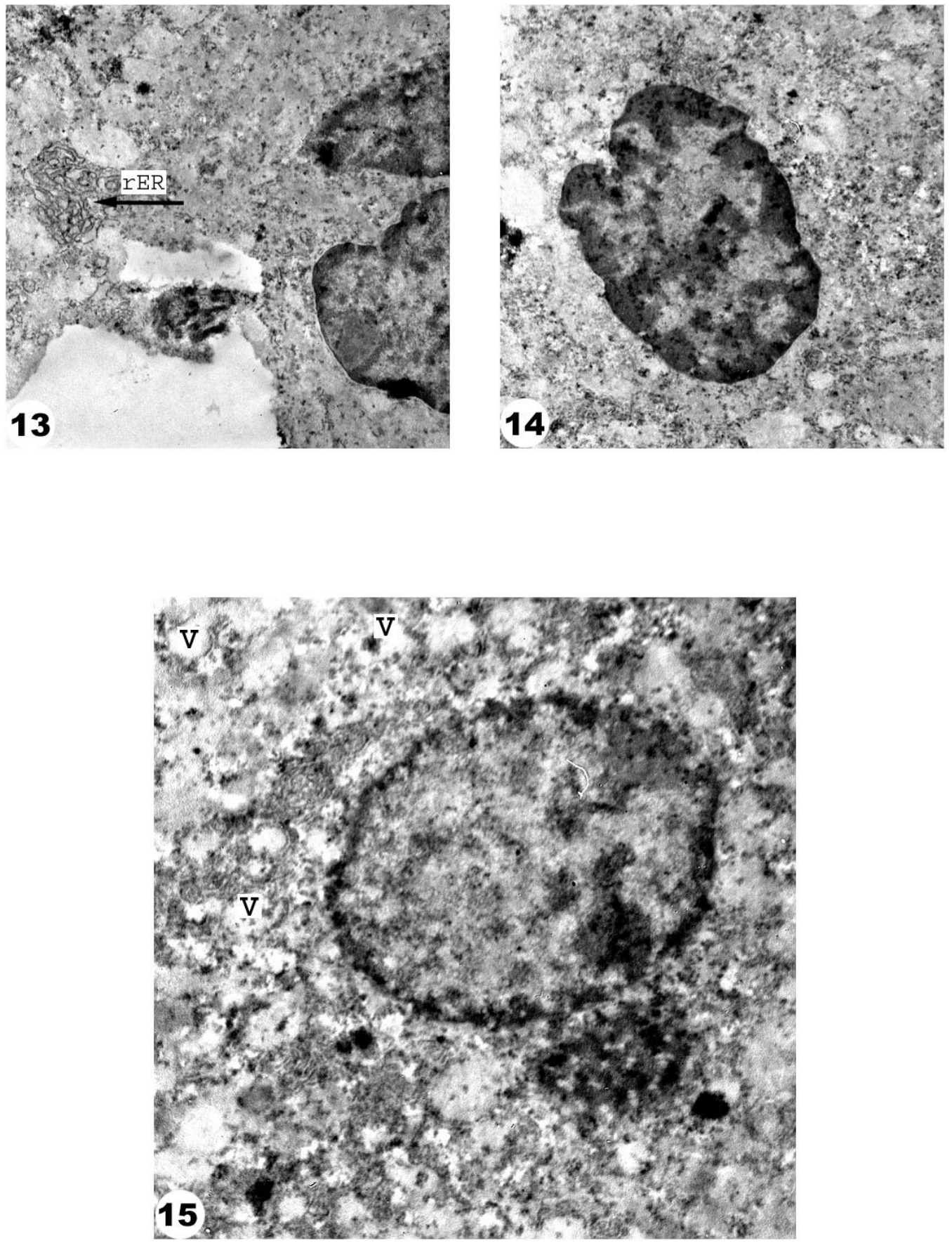


\section{Neveen Hussein Mahmoud}

\section{Discussion}

How can electromagnetic field affect organ functions and induce cellular changes ?

Is a question which has no definite answer. However various mechanisms have been suggested that E.M.F. might amplify electric currents in tissues and cells or effect through resonance with local field focus.(Sagan,1992)

Another possibility is that E.M.F. may interact with intracellular magnetic field, while the presence of magnetic impulse in human tissue has been reported. (Sonnier et al.,2000)

In the present study, the low frequency E.M.F. $50 \mathrm{HZ}$ was chosen because it has been encountered in many places, medical practice and new technologies in use nowadays (Juntilainen, 1991). The present results showed that the ultrastructure of mouse liver exposed to 50 HZ/AC E.M.F. for 20 days/8 hours daily has lead to severe degenerated hepatocytes i.e vacuolated cytoplasm, marked reduction in cytopl-asmic organelles, severe shrinking and fragmentation of rough endoplasmic retic-ulum (rER), fusion and swollen mitochondria with disappearance of its cristea.

Sign of nuclear degeneration as well as irregular nuclear membrane bounded with clumps of heterochromatin, disruptive nuclei membrane resulting in depletion of chromatic material and its appearance in the cytoplasm. It is also clear that many cells acquired signs of cell death (apoptosis)

Similar result were reported by Mikaelane et al.,(1989), Gorczynska and Wegrzynowicz (1991) and Radi et al.,(1999). however hepatocytes seen in liver mice exposed to AC/E.M.F, represented different types of cellular degeneration caused by hydropic changes and coagulative necrosis which manifest hypoxic death of hepatocytes and passive congestion of liver(Grawford,1994)

The mitochondria and (rER) were the most main organelles revealing noticeable alteration in liver mice exposed to E.M.F, Mitochondrial swelling could be due to change of the mitochondrial membrane permeability.(Chrnysheva, 1987) reported changes in phospholipids composition of the mitochondria exposed to alternating E.M.F. which would in turn alter the permeability of their membranes.

This study is compatible with the study of (El-Kholy,1999) who exposed mice to $50 \mathrm{HZ}$ for 24 hours daily, low frequency E.M.F. and Gyx-ray, the resulted micrograph of liver mouse showed mitochondria varying in size and shape, fragmented (rER), scattered ribosomes and glycogen, vacuolated cytoplasm and electrolucent non membrane bound .

Electron micrographs of mice liver exposed to the same dose of E.M.F. and kept for one month without exposure showed severe cytoplasmic and nuclear degeneration and no sign of tissue recovery were observed compared to the normal state.

In conclusion, it seemed clearly possible that the various histopathological alteration encountered in the present study might result from hypoxic injury to hepatocytes induced due to exposure to alternating E.M.F.

In fact, further studies is needed to discover and identify more about the effect of electromagnetic field on animal biological systems.

\section{References}

1. Anderson L.E. and kaune W.T. (1988): Electric and magnetic fields at extremely low frequencies. In: Non ionizing radiation protection $2^{\text {nd }}$ edition .Sues M.J.Morrison D.A.B. Copenhagen WHO. REg. Publ. Eur.Ser.;25 175-243.

2. Chernysheva O.N. (1987): Effect of an alternating magnetic field on lipid composition, of the rat liver. Ukrain. Biokhim. Zhur. 59(3): 91-94

3. El-Kholy S.M. (1999): Effect of induced $50 \mathrm{~Hz}$ sine shape E.M.F. on white blood cell counts, nuclei, acids and tissue structural changes of mice exposed to Xirradiation. Egyptian journal of biophysics. 30-36 
4. Frankel R. B. and Blakemore R.P. (1989): Magnetite and magnetotaxis in microorganisms, Bioelectomagnetics, 10:223

5. Gorczynska E. and Wegrzynowicz R.(1991): Structural and functional changes in organelles of liver cells in rats exposed to magnetic fields. Environmental Res 4. 188198.

6. Grawford J.M.(1994): The liver and the biliary tract pathological basis of disease $5^{\text {th }}$ editurn Sawn. company, 833-843.

7. ICNIRP (2004): International Committee Non Ionizing Radiation Protection. 15 .(3): 152-157

8. Juutilainen J. (1991): Effect of low frequency magnetic fields on embryonic development and pregnancy. Scand.J work Environ.Health, 17: 147-158.

9. Maret,G.,Kiepenhener,J.and Boccara,N., Eds(1986): Biophysical effects of steady mag-netic fields, Springer Verlag, New York. $3^{\text {rd }}$.ed . 75-78

10. Mikaelian N.P.,Aleiv I.M., Stupin I.V. and Belous G.G. (1989): The effect of the liver of semi conductor IR laser with a constant magnetic field. Khirurgua 1: 85-88

11. Mohamed M.M., Attia A.A. and Shalby E.T.(2001): Effect of $50 \mathrm{~Hz}$ E.M.F. on the behavior of pregnant mice and correlation with ultrastructure and dielectric properties alteration of brain tissue. Egyptian J. of biophysics, 7:54-60.
12. NRPB, (2004): quoted from documents of the NRPB (National Radiological Protection Board) Head quarters, Chilton Did cot, Oxford shire Ox11ORQ. 15 (3): 148-154

13. Radi H.S., Helmy M.A., Kelada P.I, Shabaan M.M., Ramadan A.T. and Dorotta R.I. (1999): The effect of weak magnetic fields on mice liver. A light and ultrastructural study. Egyptian J. of biophysics, ( 1): 76-88.

14. Rivard and Deadman ,(2003): Documents of the NRPB (National Radiological Protection Board) Head quarters, Chilton Did cot, Oxford shire Ox11ORQ. Volume 15 (.3) :101-107.

15. Sagan, L.A.(1992): Epidemiological and laboratory studies of power frequency electric and magnetic fields. JAMA: 268. 625-639.

16. Simon,N.J.(1989): Biological effect of static magnetic fields International Cryogenic Materials Committee, 10: 223234.

17. Sonnier,H,Kolmytkin,O.V and Marino, A.A.(2000): Resting potential of excitable neuroblastoma cells in weak magnetic fields. Cell Mol.Life Sci.,57: 514-520.

18. Tenforde,T.S.E d.,(1979): Magnetic field effect on biological systems, Plenum Press, New York, $2^{\text {nd }}$.ed.413-434. 
دراسة تركيبية دقيقة لكبد الفأر الابيض تحث تاثير المجال المغتاطيسى

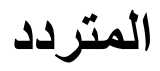

\section{نيفين حسبن محمود}

قسم علم الحيوان - كلية العلوم - فرع البنات - جامعة الأزهر

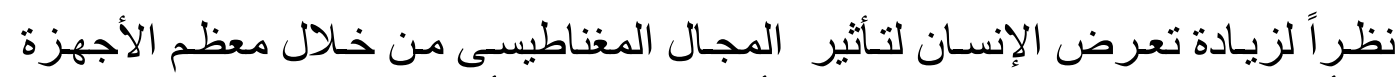

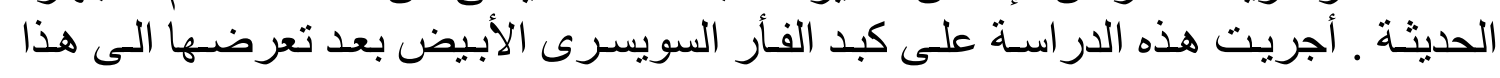

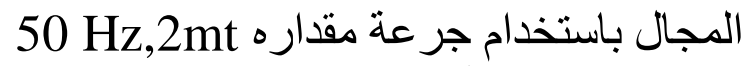

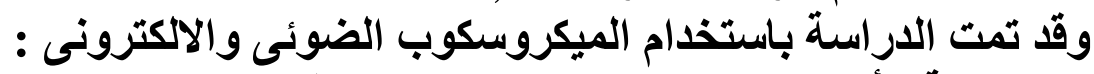

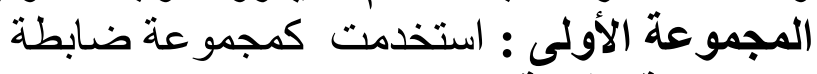

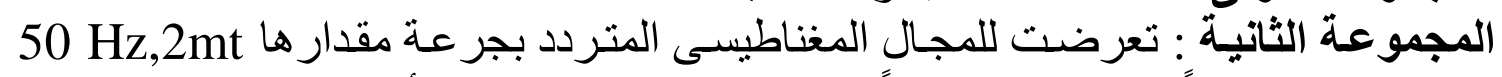

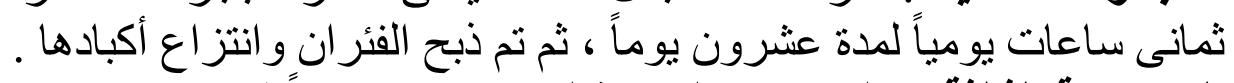

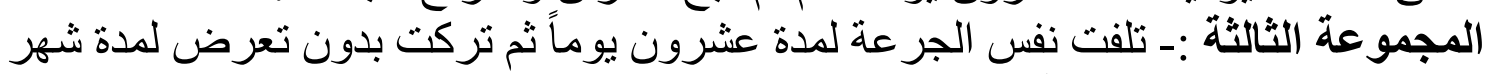

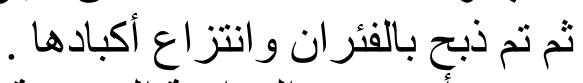

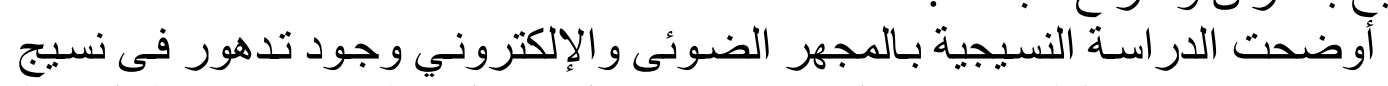

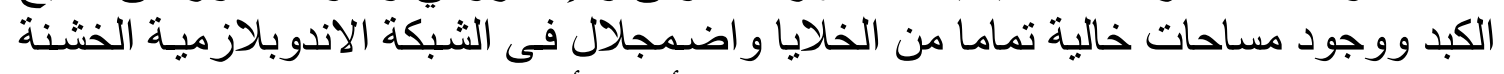

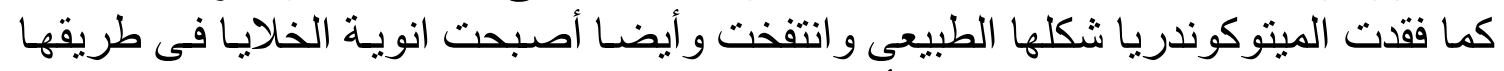

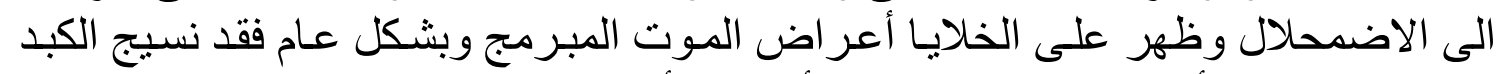

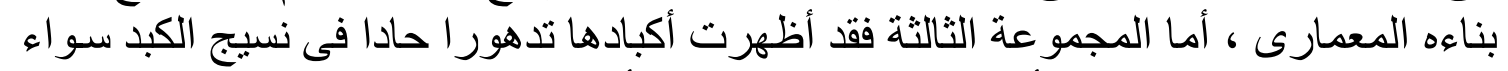

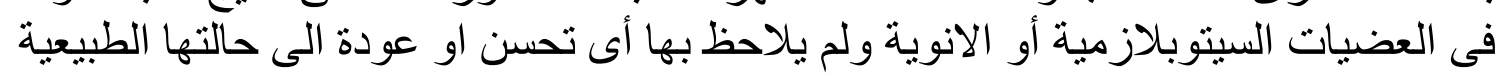
وقد دلت هذه التغير ات التى حدثت لخلايا كبد الفار السويسرى الابيض على قلة إمداد

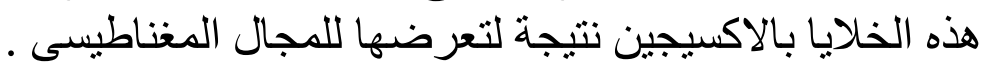

